\title{
Assessment of the maximum allowed acid deposition load at current stage in China
}

\author{
Bingwen Li, Zhangwei Wang, Xiaoshan Zhang* \\ Research Center for Eco-environmental Sciences, Chinese Academy of Sciences, Beijing 100085, China. E-mail: bwli@qq.com
}

\section{A R T I C L E I N F O}

Article history:

Received 20 December 2015

Revised 13 January 2016

Accepted 1 June 2016

Available online 25 October 2016

Keywords:

Acid deposition

Stage maximum load

Critical load

\begin{abstract}
A B S T R A C T
Soil acidification caused by acid deposition has been significant in some forests in southern China. We present an approach for assessing the current stage maximum allowed load (SML) of acid deposition for terrestrial system in the country. The main idea was that soil base cation exchange as a finite buffer to acidity was included in the soil acidity mass balance calculation at current acidification stage. We calculated the SML for five forests in southern China. The usual critical loads for the same forests were also calculated by the steady state mass balance model for comparison. The results showed that the SML is a more tolerant limit than the critical load for the forests with soils not acidified seriously at current stage. However, the SML become a more stringent limit to acid deposition when the forest soils have acidified seriously to very low base cation saturation. In this case the SML assessment is beneficial for the soils recovering from a serious acidified state. Based on a national scale database, the SML mapping for non-agricultural soil system in China was carried out.

(C) 2016 The Research Center for Eco-Environmental Sciences, Chinese Academy of Sciences. Published by Elsevier B.V.
\end{abstract}

\section{Introduction}

Acid rain has prevailed in China since 1980s and remains an environmental problem of concern by so far although some progress in controlling the emissions of $\mathrm{SO}_{2}$ has been made across the country. Soil acidification caused by acid deposition has been significant in some forests in southern China (Larssen and Carmichael, 2000; Larssen et al., 2006). So a reasonable estimation of the current stage maximum allowed load (SML) of acid deposition is necessary for the policy making of the emission reduction. The SML should be a quantitative estimate the maximum load of acid deposition under which the harmful effects on sensitive receptors are not to occur during a certain stage from now on.

As an important tool available for acid deposition control planning the assessment of the critical load (CL) of acid deposition has been carried in Europe, North America and Asia (Hettelingh et al., 1995; McNulty et al., 2007; McDonnell et al., 2010; UBA, 2004; Barkman and Alveteg, 2001; Hettelingh et al., 2004). Conceptually the critical load of acid deposition is the maximum deposition of acidifying compounds that will not cause chemical changes leading to long-term harmful effects on ecosystem structure and function (Sverdrup and DeVries, 1994). The assessment of the critical load is usually for a "long-term" steady-state condition and in corresponding to an infinite buffer, such as soil base cation weathering. The finite buffer to acidity attributed to soil base cation exchange does not effect on the critical load calculation.

Different models such as steady state mass balance model (SSMB) (Li and McNulty, 2007; Skeffington, 2006; Skeffington et al., 2006; Sverdrup and DeVries, 1994; UBA, 2004) and the dynamic model MAGIC (Cosby et al., 1985) have been used to assess the critical load in China (Zhao and Seip, 1991; Hettelingh et al., 1995; Duan et al., 2000, 2001; Larssen et al., 2000; Liao et al., 1998; Xie et al., 1995; Zhao et al., 1995, 2007a, 2007b). The critical load derived from these models is the

\footnotetext{
* Corresponding author. E-mail: zhangxsh@rcees.ac.cn (Xiaoshan Zhang).
} 
maximum allowed acid deposition load for a soil-water system at a critical steady state specified by a chemical criterion (Skjelkvåle et al., 2005).

However, during soil acidification or restoration processes the consumption of soil alkalinity represented by base cation exchange provides a finite buffer and governs the long-term changes in soil and soil solution chemistry (UBA, 2004). So the soil base cation exchange should not be ignored in calculating the maximum allowed acid deposition load for the current stage of a few decades (e.g., twenty years).

In this paper, we present an approach for assessing the current SML of acid deposition. In the model calculation the base cation exchange flux $\left(\mathrm{ANC}_{\mathrm{EX}}\right)$ as a finite buffer to acidity was combined with a critical chemical criterion in a simple stable process model. The purpose of the work is to provide a tool improvement for policy development of acid deposition control. We assessed the SML for five forested small catchments in southern China. The mapping of the current SML of acid deposition for non-agricultural soil system all over China was also performed.

\section{Approach}

The model which we proposed for calculating the SML of acid deposition is based on a simple soil acidity mass balance. We assumed that under the SML a soil system experiences a stable acidifying or restoring process for a stage of $n$ years from current state to arrive at the state specified by critical soil base saturation $\left(\mathrm{BS}_{\text {crit }}\right)$, and the soil structure keeps stable. During the process soil alkalinity consumption represented by soil base cation exchange flux is assumed to be constant and depends on the current and critical soil base saturation and the time scope ( $n$ years) set for the current stage. So it is a simple stable process model in nature.

The SML was derived from the acidity mass balance by the similar steps as for critical load in SSMB model (Sverdrup and DeVries, 1994; UBA, 2004). The difference is that base cation exchange flux (ANC $\mathrm{EX}_{\mathrm{EX}}$ ) as a finite buffer to acid is considered. The acid deposition flux $\left(A C_{D}\right)$ is attributed to the deposition of $\mathrm{S}$ and $\mathrm{N}$. $\mathrm{NH}_{4}^{+}$is considered to be acidic which is produced through nitrification in soil and plant uptake (Sverdrup and DeVries, 1994).

$\mathrm{SML}=\mathrm{BC}_{\mathrm{W}}+\mathrm{ANC}_{\mathrm{EX}, \max }-\mathrm{BC}_{\mathrm{U}}+\left(1-f_{\mathrm{DE}}\right) \times\left(\mathrm{N}_{\mathrm{I}}+\mathrm{N}_{\mathrm{U}}\right)-\mathrm{ANC}_{\mathrm{L}, \text { crit }}$

$\mathrm{AC}_{\mathrm{D}}=\mathrm{SO}_{4}{ }^{2-}+\left(1-f_{\mathrm{DE}}\right) \times\left(\mathrm{NO}_{3}{ }^{-}+\mathrm{NH}_{4}{ }^{+}\right)-\mathrm{BC}_{\mathrm{D}}$

where, $\mathrm{BC}_{\mathrm{W}}$ (keq/(ha-year)) is base cation weathering rate from soil minerals, $\mathrm{ANC}_{\mathrm{EX}, \max }(\mathrm{keq} /(\mathrm{ha} \cdot \mathrm{year})$ ) is the maximum allowed alkalinity production flux from soil base cation exchange, $\mathrm{BC}_{\mathrm{U}}(\mathrm{keq} /$ (ha.year)) the base cation uptake by soil, $f_{\mathrm{DE}}$ is the denitrification fraction, $\mathrm{BC}_{\mathrm{D}}$ (keq/(ha.year)) is the base cation deposition, $N_{\text {I }}$ (keq/(ha.year)) is net nitrogen immobilization rate, $N_{\mathrm{U}}$ (keq/(ha.year)) is net nitrogen uptake by vegetation, $\mathrm{ANC}_{\mathrm{L}, \mathrm{crit}}(\mathrm{keq} /$ (ha.year)) the critical alkalinity leaching from soil.

Assuming that effective soil cation exchange capacity (CEC) keeps constant and the decline of soil base saturation
(BS) is linear during the current stage (n years), the maximum allowed value of alkalinity production flux from soil base cation exchange $\mathrm{ANC}_{\mathrm{EX}, \max }$ can be expressed as:

$\mathrm{ANC}_{\mathrm{EX}, \max }=\left(\mathrm{BS}-\mathrm{BS}_{\text {crit }}\right) \times \mathrm{CEC} \times \rho_{\mathrm{b}} \times \mathrm{H} / n$

where, $\mathrm{BS}_{\text {crit }}(\%)$ is critical soil base saturation, $\rho_{\mathrm{b}}\left(\mathrm{kg} / \mathrm{m}^{3}\right)$ is volume weight of soil, $H(\mathrm{~cm})$ is the thickness of root layer, and $n$ is the number of years set to a current stage, which serves as an option for planning acid deposition control.

It is obvious that $\mathrm{ANC}_{\mathrm{EX}, \max }$ tends to be zero if the current stage is set to be infinite. In this case the current SML tends to be the same as CL.

For acidic soil, the critical alkalinity leaching flux, $\mathrm{ANC}_{\mathrm{L}, \mathrm{crit}}$, can be the $\mathrm{Al}^{3+}$ plus $\mathrm{H}^{+}$leaching at the critical state specified.

$\mathrm{ANC}_{\mathrm{L}, \text { crit }}=-\mathrm{Al}_{\mathrm{L}, \mathrm{crit}}^{3+}-\mathrm{H}_{\mathrm{L}, \mathrm{crit}}^{+}$

The parameterization scheme for $\mathrm{Al}_{\mathrm{L} \text {, crit }}^{3+}$ can be derived from 'Soil stability criterion', which assumes that aluminum leaching equals to aluminum weathering $\left(\mathrm{Al}_{\mathrm{w}}\right)$ and equals to the twice of total base cation weathering (Sverdrup

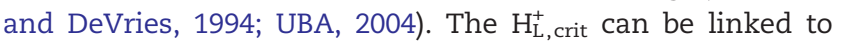
$\mathrm{Al}_{\mathrm{L}}^{3+}$,rit based ongibbsite equilibrium (UBA, 2004). Gibbsite equilibrium is highly site-specific (Alveteg et al., 1995). So it would be better to employ the $\mathrm{pH}-\mathrm{pAl}$ relation from empirical analysis (Zhao et al., 2007a):

$$
\begin{aligned}
& \mathrm{ANC}_{\mathrm{L}, \text { crit }}=-\mathrm{Al}_{\mathrm{W}}-\mathrm{Q} \times\left[\mathrm{Al}_{\mathrm{W}} /(\mathrm{Q} \times \mathrm{K})\right]^{1 / \alpha} \\
& \mathrm{Al}_{\mathrm{W}}=p \times \mathrm{BC}_{\mathrm{W}} \\
& \mathrm{K}=\left[\mathrm{Al}^{3+}\right] /\left[\mathrm{H}^{+}\right]^{\alpha}
\end{aligned}
$$

where, $\mathrm{Q}\left(\mathrm{m}^{3} /\right.$ (ha.year) ) is the water flux through the root zone in soil profile, $\mathrm{K}$ and $\alpha$ are the empirical coefficients for $\mathrm{pH}-\mathrm{pAl}$ correlation, $p$ is the stoichiometric ratio of aluminum to base cation from chemical weathering of primary minerals.

\section{Results}

\subsection{Assessing the stage maximum load at five sites in southern China}

We assessed the SML by the model for five forested small catchments in southern China (Fig. 1), where monitoring of acid deposition and soil-water acidification have been conducted for years. The data are available for the model calculation (Larssen et al., 2004; Zhao et al., 2007b).

The studied sites are all located within the acid rain control zone in southern China. The yellow soil in these sites is dominate, which is sensitive to acid deposition. The site Tieshanping (TSP) is forested with pine and receives large sulfate and nitrogen deposition (Larssen et al., 2004). The site Liuchongguan (LCG) is also forested with pine, located in urban area of Guiyang city. The site Leigongshan (LGS) is located in a remote mountain region of Guizhou Province with receiving lowest $\mathrm{S}$ and $\mathrm{N}$ deposition among these sites. The site Caijiatang (CJT) is a pine forest in Hunan Province. Liuxihe 


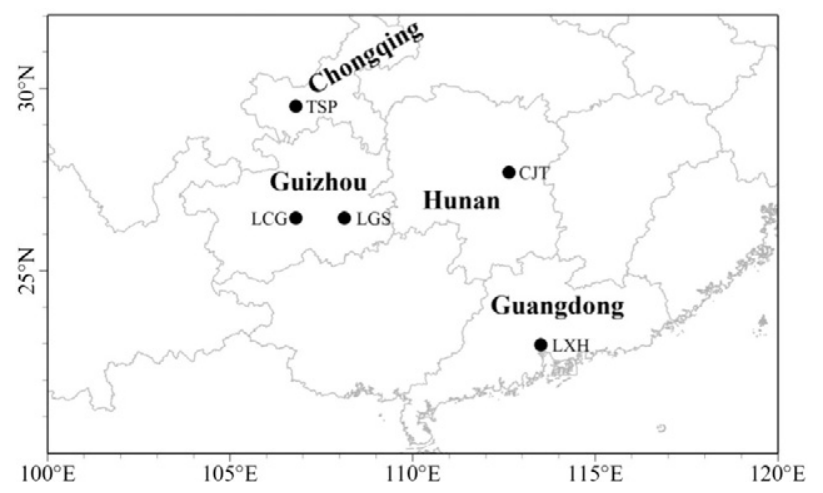

Fig. 1 - Location of the five catchments in China. TSP: Tieshanping, LCG: Liuchongguan, LGS: Leigongshan, CJT: Caijiatang, LXH: Liuxihe.

(LXH) is a broad leaf evergreen forest in Guangdong Province. At these sites, sulfate is the dominating anion and calcium the major cation in wet deposition. The sulfatede position ranges from 1.5 to $10.5 \mathrm{keq} /$ (ha.year), the calcium deposition ranges from 0.8 to $5.7 \mathrm{keq} /$ (ha.year) both highest in TSP and lowest in LGS (Larssen et al., 2004, 2011). The volume weighted $\mathrm{pH}$ ranges from 4.1 to 4.7 highest in TSP and lowest in LGS. The base saturation in these sites ranges from $44.8 \%$ to $9.8 \%$ highest in LGS and lowest in TSP.

We firstly calculated the maximum allowed alkalinity production $n \cdot \mathrm{ANC}_{\mathrm{EX}, \max }$ from soil base cation exchange in the catchments by Eq. (3). The results and the input data for the calculation were listed in Table 1 . According to previous study (Holmberg et al., 2001) $\mathrm{BS}_{\text {crit }}$ was set to $15 \%$ of the effective soil CEC, which is the level deemed to avoid nutrient deficiencies for plants. The maximum allowed alkalinity production in the five sites ranges from -9.71 to $53.85 \mathrm{keq} /$ ha. The LGS site has the largest value own to the highest base saturation. The base saturation at TSP site is the smallest and gets to the lowest value of the maximum allowed alkalinity production. The values of $n \cdot \mathrm{ANC}_{\mathrm{EX}, \max }$ are negative in TSP and LXH due to the BS lower than the critical value.

We calculate the current SML for the five small catchments in three cases (SML-20, SML-40 and SML-80), which correspond to 20,40 and 80 years ( $n=20,40$ or 80 ) of the current stage, respectively. The critical load (CL) was also calculated by steady state mass balance (SSMB) model for comparison. As indicated previously the time scope ( $n$ years) set for current stage was an option of acid deposition control.

The input data for calculating the SML and CL were same as listed in Table 2. In our calculation the $\mathrm{pH}-\mathrm{pAl}$ equilibrium

Table 1-Total alkalinity production allowed from soil base cation exchange at the five sites.

\begin{tabular}{llllll} 
& TSP & LCG & LGS & CJT & LXH \\
\hline CEC $(\mathrm{ceq} / \mathrm{kg})$ & 4.582 & 9.5 & 7.423 & 3.849 & 1.947 \\
$\mathrm{BS}(\%)$ & 9.8 & 21.34 & 44.79 & 19.83 & 14.17 \\
$\rho_{\mathrm{b}}\left(\mathrm{kg} / \mathrm{m}^{3}\right)$ & 1455 & 978 & 738 & 1088 & 836 \\
$\mathrm{BS}_{\mathrm{crit}}(\%)$ & 15 & 15 & 15 & 15 & 15 \\
$\mathrm{H}(\mathrm{cm})$ & 28 & 39 & 33 & 34 & 34 \\
$n \cdot A N C_{\text {EX,max }}$ & -9.71 & 22.97 & 53.85 & 6.88 & -0.46 \\
\hline
\end{tabular}

CEC: cation exchange capacity, BS: soil base saturation.
Table 2 - Data for calculating the current stage maximum allowed load at the five sites.

\begin{tabular}{|c|c|c|c|c|c|}
\hline & TSP & LCG & LGS & CJT & LXH \\
\hline $\mathrm{BC}_{\mathrm{W}}(\mathrm{keq} /($ ha $\cdot$ year $))$ & 0.6 & 0.65 & 1.29 & 1.05 & 2.19 \\
\hline $\mathrm{BC}_{\mathrm{U}}(\mathrm{keq} /(\mathrm{ha} \cdot \mathrm{year}))$ & 0.25 & 0.25 & 0.58 & 0.31 & 2.48 \\
\hline $\log K$ & 2.69 & 2.69 & 2.69 & 2.69 & 2.69 \\
\hline$\alpha$ & 1.63 & 1.63 & 1.63 & 1.63 & 1.63 \\
\hline$p$ & 2 & 2 & 2 & 2 & 2 \\
\hline $\mathrm{Q}\left(\mathrm{m}^{3} /(\right.$ ha $\cdot$ year $\left.)\right)$ & 5220 & 6300 & 10170 & 3860 & 7810 \\
\hline$N_{U}(\mathrm{keq} /($ ha $\cdot$ year $))$ & 0.21 & 0.21 & 0.59 & 0.26 & 2 \\
\hline $\mathrm{N}_{\mathrm{I}}$ (keq/(ha·year)) & 0.17 & 0.16 & 0.14 & 0.13 & 0.05 \\
\hline$f_{D E}$ & 0.8 & 0.8 & 0.8 & 0.8 & 0.8 \\
\hline
\end{tabular}

coefficients were derived from a logarithm-linear regression based on monthly averaged monitoring data of soil-water chemistry (Larssen et al., 2004; Zhao et al., 2007b).

The results of the calculation were showed in Fig. 2. The maximum allowed acid deposition load for 20 years of current stage (SML-20) at the five sites ranges from 1.82 (TSP) to 6.71 (LGS) keq/(ha.year). The critical load ranges from 2.31 (TSP) to 6.27 (LXH) keq/(ha.year). The SML values tend to decrease with the time scope extension and get to the minimum, the critical load, at LGS, LCG and CJT sites where the BS is above its critical value and so the $\mathrm{ANC}_{\mathrm{EX}}$ is positive, i.e., SML- $20 \geqq S M L-40 \geqq S M L-80 \geqq C L$. In contrast, the values of SML tend to increase with the time scope extension of the current stage and get to the maximum, the critical load (CL) for TSP and LXH sites where $\mathrm{ANC}_{\mathrm{EX}}$ is negative, i.e., SML- $20 \leqq$ SML- $40 \leqq$ SML- $80 \leqq$ CL.

\subsection{Mapping the stage maximum loads in China}

For calculating and mapping a regional stage maximum acid deposition load the key step is the data acquisition of the soil parameters over the region.

In this work, the data of BS and CEC came from our field investigation in south and northeast China combined into 2nd National Soil Survey (Xiong and Li, 1987a,b) (Fig. S1). We used the same data of base cation weathering rate as in the work by Duan et al. (2002). The weathering rate of Al was set to the twice of base cation weathering rate (Cosby et al., 1985) as there were no any measurements of $\mathrm{Al}$ weathering rate in China. For base cation and nitrogen uptake rate by plant growth the dataset is same as in the work by Duan et al.

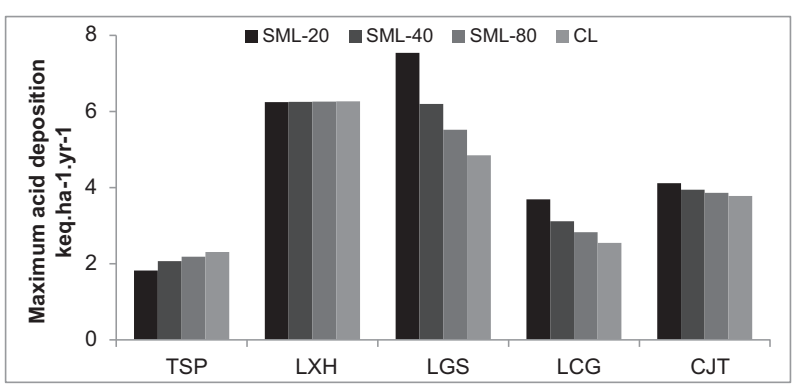

Fig. 2 - The maximum allowed acid deposition load for current stage 20, 40 and 80 years, and critical loads (SML-20, SML-40, SML-80 and CL, SML: current stage maximum allowed load, CL: the critical load). 
(2004). The soil thickness of root layer $(H)$ was defined from literature (Wang et al., 2001).

BS in northern China was usually greater than that in the south (Fig. S1a). There is little base cation leaching from soil in Northern and North western China, because the surface runoff is rare. BS was less than $30 \%$ in most regions in southern China except few areas in the southwest where mainly distribution with limy soil. In nearly $20 \%$ areas of the region, base saturation of natural soil was less than $15 \%$.

The BS in northern China was much higher than that in south China (Tao and Feng, 2000), in most regions which are nearly $100 \%$. Only in rarely region of northeast of China where covered by virgin forest, BS was less than $30 \%$. This is according to the soil type and surface runoff. In northern China, soils are carbonated-rich and saline. Meanwhile, depth of surface runoff in the regions is much shallow than in southern China. CEC ranges from 4 to $48.36 \mathrm{ceq} / \mathrm{kg}$ (Fig. S1b). CEC in the southeast and the northwest China was almost no more than $15 \mathrm{ceq} / \mathrm{kg}$, CEC in majority areas of the region was no more than $5 \mathrm{ceq} / \mathrm{kg}$. But CEC in the west, middle and the northeast of China is higher than in southeast and northwest. In regions of Northern plain, CEC of soil is more than $35 \mathrm{ceq} / \mathrm{kg}$. In general, the rule of CEC distribution is not obvious like that of base saturation.

For the current stage of twenty years the maximum allowed base cation exchange flux ( $\mathrm{ANC}_{\mathrm{EX}, \mathrm{max}}$ ) and acid deposition load (SML-20) were calculated and mapped by spatial analysis in ArcGIS based on the data input above (Fig. S2a and b).

$\mathrm{ANC}_{\mathrm{EX} \text {,max }}$ is less than $5 \mathrm{keq} /$ (ha.year) in most of southern China and part of northwestern China (Fig. S2a), where the base saturation is lower. The high $\mathrm{ANC}_{\mathrm{EX} \text {,max }}$ values, greater than $35 \mathrm{keq} /$ (ha.year), appear to some areas in northern and northeastern China, where both base saturation and CEC are high. The distribution rule of $\mathrm{ANC}_{\mathrm{EX}, \max }$ is similar with base saturation. But in small regions of the northwest where the base saturation is nearly $100 \%$, the $\mathrm{ANC}_{\mathrm{EX}, \max }$ is less than $5 \mathrm{keq} /$ (ha.year), which is much lower compare with that in Northern and Northeastern China, because of the low CEC of soil in the regions.

The SML-20 increases gradually from the south to the north of China (Fig. S2b). SML-20 is less than $2 \mathrm{keq} /$ (ha.year) in most regions of Southern China, which means the region is very sensitive to acid deposition. The values of SML-20 lower than $1 \mathrm{keq} /$ (ha.year) appear in some areas in Southwestern China and sporadically in Northeastern. The values of SML-20 is usually greater than $5 \mathrm{keq} /$ (ha.year), even more than $10 \mathrm{keq} /$ (ha.year) in most areas of Northern China, which means these regions are not sensitive to acid deposition. It is generally that the wet region covered with forest in south and northeast of China gets much lower stage maximum loads than that of the arid region in northern China.

\section{Discussion}

As noted above that soil base cation exchange provides a finite buffer and governs the long-term changes in soil and soil solution chemistry. In early study the capacity of exchangeable cation was an important parameter in assessing soil sensitivity to acid deposition. So in this paper the alkalinity production from soil base cation exchange was involved in deriving the maximum allowed acid deposition load at current stage of a few decades.

The contribution to SML from maximum allowed soil base cation exchange, $\mathrm{ANC}_{\mathrm{EX} \text {,max }}$ varied largely from one forest site to another, but was significant (Table 1 and Fig. 2). ANC EX,max $_{\text {max }}$ contributed more than $-20 \%$ of SML-20 at TSP where it gets to very low soil BS and low CEC. In contrast at LGS, the maximum allowed base cation exchange, $\mathrm{ANC}_{\mathrm{EX}, \max }$ contributed $40 \%$ to SML-20, where BS gets to about $45 \%$.

Distribution of the stage maximum loads (SML-20) we calculated in China was similar to the critical load (CL) by Duan et al. (2001), but SML-20 is several times larger than CL in northern and northwestern China. SML-20 is slightly higher than CL in southern China, but in some areas SML-20 lower than CL due to a negative finite buffer to acidity there (Fig. S2).

The results showed that the SML is a more tolerant limit than the critical load for the forests with soils that are not acidified seriously ( $\mathrm{BS} \geqq \mathrm{BS}_{\text {crit }}$ ) at current stage. However, the SML becomes a more stringent limit to acid deposition when the forest soils have acidified seriously to a very low base cation saturation ( $\mathrm{BS} \leqq \mathrm{BS}_{\text {crit }}$ ). In this case the $\mathrm{SML}$ assessment is beneficial for the soils recovering from a serious acidified state.

\section{Conclusions}

We developed a simple stable process mass balance model for assessing the maximum allowed load of acid deposition for soils at current stage (SML), which involves the soil base cation exchange as a finite buffer to acidity, critical soil base saturation and the soil stability criterion.

By applying the model to the forests in southern China we can conclude that the soil base cation exchange was important in assessing the maximum acid deposition load of forest soils, which is concerned for current stage in China.

We can also conclude that the SML is a more stringent limit to acid deposition for the forests with soils acidified seriously, and a tolerant limit for the forests with soils not acidified seriously.

\section{Acknowledgments}

This work was supported by Knowledge Innovation Project of The Chinese Academy of Sciences (No. KZCXZ-YW-GJ01) and The National Basic Research Program (973) of China (No. 2005CB422206).

\section{Appendix A. Supplementary data}

Supplementary data to this article can be found online at http://dx.doi.org/10.1016/j.jes.2016.05.047.

\section{R E F E R E N C E S}

Alveteg, M., Sverdrup, H., Warfvinge, P., 1995. Developing a kinetic alternative in modeling soil aluminium. Water Air Soil Pollut. 79 (1), 377-389. 
Barkman, A., Alveteg, M., 2001. Identifying potentials for reducing uncertainty in critical load calculations using the PROFILE model. Water Air Soil Pollut. 125 (1), 33-54.

Cosby, B., Hornberger, G., Galloway, J., Wright, R., 1985. Modelling the effects of acid deposition: assessment of a lumpedparameter model of soil water and streamwater chemistry. Water Resour. Res. 21 (1), 51-63.

Duan, L., Hao, J., Xie, S., Zhou, Z., Ye, X., 2002. Determining weathering rates of soils in China. Geoderma 110 (3-4), 205-225.

Duan, L., Xie, S., Zhou, Z., Hao, J., 2000. Critical loads of acid deposition on soil in China. Water Air Soil Pollut. 118 (1), 35-51.

Duan, L., Xie, S., Zhou, Z., Ye, X., Hao, J., 2001. Calculation and mapping of critical loads for $\mathrm{S}, \mathrm{N}$ and acidity in China. Water Air Soil Pollut. 130 (1), 1199-1204.

Duan, L., Huang, Y., Hao, J., Xie, S., Hou, M., 2004. Vegetation uptake of nitrogen and base cations in China and its role in soil acidification. Sci. Total Environ. 330 (1-3), 187-198.

Hettelingh, J.-P., Slootweg, J., Posch, M., 2004. Critical loads and dynamic modelling results. CCE Progress Report 2004.

Hettelingh, J.-P., Sverdrup, H., Zhao, D., 1995. Deriving critical load for Asia. Water Air Soil Pollut. 85 (4), 2565-2570.

Holmberg, M., Mulder, J., Posch, M., Starr, M., Forsius, M., Johansson, M., et al., 2001. Critical loads of acidity for forest soils: tentative modifications. Water Air Soil Pollut. 1 (1), 91-101.

Larssen, T., Carmichael, G., 2000. Acid rain and acidification in China: the importance of base cation deposition. Environ. Pollut. 110 (1), 89-102.

Larssen, T., Duan, L., Mulder, J., 2011. Deposition and leaching of sulfur, nitrogen and calcium in four forested catchments in China: implications for acidification. Environ. Sci. Technol. 45 (4), 1192-1198.

Larssen, T., Lydersen, E., Tang, D., He, Y., Gao, J., Liu, H., et al., 2006. Acid rain in China. Environ. Sci. Technol. 40 (2), 418-425.

Larssen, T., Schnoor, J., Seip, H., Zhao, D., 2000. Evaluation of different approaches for modeling effects of acid rain on soils in China. Sci. Total Environ. 246 (2-3), 175-193.

Larssen, T., Tang, D., He, Y., 2004. Integrated monitoring program on acidification of Chinese terrestrial systems-IMPACTS. Annual Report Results 2003. Norwegian Institute for Water Research, Oslo.

Li, H., McNulty, S., 2007. Uncertainty analysis on simple mass balance model to calculate critical loads for soil acidity. Environ. Pollut. 149 (3), 315-326.

Liao, B., Larssen, T., Seip, H., 1998. Response of five Chinese forest soils to acidic inputs: batch experiment. Geoderma 86 (3-4), 295-316.
McDonnell, T., Cosby, B., Sullivan, T., McNulty, S., Cohen, E., 2010. Comparison among model estimates of critical loads of acidic deposition using different sources and scales of input data. Environ. Pollut. 158 (9), 2934-2939.

McNulty, S., Cohen, E., Myers, J., Sullivan, T., Li, H., 2007. Estimates of critical acid loads and exceedances for forest soils across the conterminous United States. Environ. Pollut. 149 (3), 281-292.

Skeffington, R., 2006. Quantifying uncertainty in critical loads: (a) literature review. Water Air Soil Pollut. 169 (1), 3-24.

Skeffington, R., Whitehead, P., Abbott, J., 2006. Quantifying uncertainty in critical loads: (B) acidity mass balance critical loads on a sensitive site. Water Air Soil Pollut. 169 (1), 25-46.

Skjelkvåle, B., Stoddard, J., Jeffries, D., Tørseth, K., Høgåsen, T., Bowman, J., et al., 2005. Regional scale evidence for improvements in surface water chemistry 1990-2001. Environ. Pollut. 137 (1), 165-176.

Sverdrup, H., DeVries, W., 1994. Calculating critical loads for acidity with the simple mass balance method. Water Air Soil Pollut. 72 (1), 143-162.

Tao, F., Feng, Z., 2000. Terrestrial ecosystem sensitivity to acid deposition in South China. Water Air Soil Pollut. 118 (3), 231-244.

UBA, 2004. Manual on Methodolgies and Criteria for Modelling and Mapping Critical Loads and Levels and Air Pollution Effects, Risk and Trends. Umweltbundesamt, Berlin.

Wang, S., Zhu, S., Zhou, C., 2001. Characteristics of spatial variability of soil thickness in China. Geogr. Res. 20 (2), 161-169.

Xie, S., Hao, J., Zhou, Z., Qi, L., Yin, H., 1995. Assessment of critical loads in Liuzhou, China using static and dynamic models. Water Air Soil Pollut. 85 (4), 2401-2406.

Xiong, Y., Li, Q., 1987a. Chinese Soils. Science Press, Beijing, China.

Xiong, Y., Li, Q., 1987b. Chinese Soils. 2nd Ed. Science Press, Beijing, China.

Zhao, D., Seip, M., 1991. Assessing effects of acid deposition in southwestern China using the MAGIC model. Water Air Soil Pollut. 60 (1), 83-97.

Zhao, Y., Duan, L., Larssen, T., Hu, L., Hao, J., 2007a. Simultaneous assessment of deposition effects of base cations, sulfur, and nitrogen using an extended critical load function for acidification. Environ. Sci. Technol. 41 (6), 1815-1820.

Zhao, Y., Duan, L., Larssen, T., Mulder, J., Hu, L., Hao, J., 2007b. Calculating critical loads for acidification for five forested catchments in China using an extended steady state function. Sci. Total Environ. 387 (1-3), 54-67.

Zhao, D., Zhang, X., Yang, J., Mao, J., Xiong, J., 1995. Critical load of sulfur deposition for ecosystem and its application in China. J. Environ. Sci. 7 (3), 325-337. 